\title{
Association between NLPR1, NLPR3, and P2X7R Gene Polymorphisms with Partial Seizures
}

\author{
Haidong Wang, ${ }^{1}$ Pengfei Xu, ${ }^{2}$ Dehua Liao, ${ }^{3}$ Ruili Dang, ${ }^{2}$ Xin He, \\ Yujin Guo, ${ }^{2}$ and Pei Jiang ${ }^{2}$ \\ ${ }^{1}$ Department of Pharmacy, The First People's Hospital of Lianyungang, The Affiliated Hospital of Kangda College of \\ Nanjing Medical University, Jiangsu, Lianyungang 222002, China \\ ${ }^{2}$ Institute of Clinical Pharmacy \& Pharmacology, Jining First People’s Hospital, Jining Medical University, Jining 272000, China \\ ${ }^{3}$ Department of Pharmacy, Hunan Cancer Hospital, Central South University, Changsha 410011, China \\ ${ }^{4}$ Department of Pharmacy, Second Xiangya Hospital, Central South University, Changsha 410010, China
}

Correspondence should be addressed to Pei Jiang; jiangpeicsu@sina.com

Received 5 January 2017; Accepted 6 April 2017; Published 19 April 2017

Academic Editor: Nobuo Kanazawa

Copyright (C) 2017 Haidong Wang et al. This is an open access article distributed under the Creative Commons Attribution License, which permits unrestricted use, distribution, and reproduction in any medium, provided the original work is properly cited.

Objectives. Clinical and experimental evidence has clarified that the inflammatory processes within the brain play a pivotal role in the pathophysiology of seizures and epilepsy. Inflammasomes and P2X7 purinergic receptor (P2X7R) are important mediators during the inflammatory process. Therefore, we investigated the possible association between partial seizures and inflammasomes NLPR1, NLRP3, and P2X7R gene polymorphisms in the present study. Method. A total of 163 patients and 201 health controls were enrolled in this study and polymorphisms of NLPR1, NLRP3, and P2X7R genes were detected using polymerase chain reaction(PCR-) ligase detection reaction method. Result. The frequency of rs878329 (G>C) genotype with C (CG + CC) was significantly lower among patients with partial seizures relative to controls $(\mathrm{OR}=2.033,95 \% \mathrm{CI}=1.290-3.204, p=0.002$ for $\mathrm{GC}+\mathrm{CC}$ versus GG). Intriguingly, we found that the significant difference of $\operatorname{rs} 878329$ (G>C) genotype and allele frequency only existed among males $(\mathrm{OR}=2.542,95 \% \mathrm{CI}=1.344-4.810, p=0.004$ for $\mathrm{GC}+\mathrm{CC}$ versus $\mathrm{GG})$, while there was no statistically significant difference among females. However, no significant results were presented for the genotype distributions of rs8079034, rs4612666, rs10754558, rs2027432, rs3751143, and rs208294 polymorphisms between patients and controls. Conclusion. Our study demonstrated the potentially significant role of NLRP1 rs878329 (G>C) in developing susceptibility to the partial seizures in a Chinese Han population.

\section{Introduction}

Epilepsy is an electrical disturbance in the brain characterized by uncontrollable, excessive or synchronous neuronal activity and an enduring predisposition to produce seizures $[1,2]$. It always accompanies the emotional and cognitive dysfunction and affects about 70 million people worldwide, accounting for approximately $1 \%$ of the whole population at present [3]. Partial seizure (also called focal seizure) is one of the most common forms of epilepsy and is initially focused in just one part of the brain. There are two types of partial seizures: simple partial seizures and complex partial seizures. The symptoms of the partial seizures depend on the base of where the seizure occurs $[4,5]$.
Over the last decade, accumulating clinical and experimental evidence has clarified that the inflammatory processes within the brain play a pivotal role in the pathophysiology of seizures and epilepsy [6-8]. Among all the proinflammatory cytokines, the release of interleukin- (IL-) $1 \beta$ is considered as central to the initiation and regulation of inflammation [9]. Inflammasomes, multiprotein complexes consisting of proinflammatory caspase, nucleotide-binding oligomerization domain-like receptor family members containing pyrin domain (NLRP), and the adaptor molecule apoptosisassociated speck-like protein, have proved their vital role in the process of the generation of the IL- $1 \beta[10,11]$. NLRP1 and NLRP3 are the two best characterized members of inflammasomes and their activation during epilepsy has been 
documented in both basic and clinical researches [12-15]. The exact process of the activation of NLRP1 and NLRP3 is unclear, but one potential mechanism is the reduction of potassium ions in cells resulting from the dilation of the $\mathrm{P} 2 \mathrm{X} 7$ purinergic receptor- (P2X7R-) gated channel $[16,17]$. In addition, it has been indicated that P2X7R plays a pivotal role in the pathophysiology of several neuropsychiatric disorders, including the seizures $[18,19]$.

Therefore, the aim of this present study was to investigate the role of NLRP1 (rs8079034, rs878329), NLRP3 (rs4612666, rs10754558, and rs2027432), and P2X7R (rs3751143, rs208294) gene polymorphisms in Chinese partial seizures population.

\section{Materials and Methods}

2.1. Subjects. The study cohort consisted of 163 unrelated Chinese patients (male: female $=89: 74$ ) younger than 19 years and they were enrolled at the outpatient clinic of the Second Xiangya Hospital of Hunan Province from November 2013 to December 2015. The patients were diagnosed using the "Classification of Epilepsies and Epileptic Syndromes" proposed by the Commission on Classification and Terminology of the International League Against Epilepsy. The mean age at seizure onset was $4.7 \pm 2.9$ years (range $0.08-12.9$ years), and the mean duration of epilepsy was $3.1 \pm 2.3$ years (range $0-6.6$ years). The epileptologists from Second Xiangya Hospital made the diagnosis of partial seizures on the basis of a range of clinical seizure semiology, interictal and ictal EEG, typical mesial temporal auras, and MRI criteria for each patient. There were no mass malformations of cortical development, cerebral tumor, or traumatic brain lesion or injury from vascular malformation for any patients. Anyone who had mental retardation, psychiatric difficulties, or obvious mental retardations was ruled out.

201 healthy individuals (males : female $=99: 102$ ), 14 to 48 years of age, ethnicity and sex matched from the same area, were recruited to participate in the study as a control group. None of the control participants had any history of central nervous system diseases or any other medical disorders. The study protocol was approved by the local institutional ethics committee, and written informed consent was obtained from each participant in this study.

2.2. DNA Isolation and Genotyping. Genomic DNA was isolated from about $1 \mathrm{ml}$ EDTA anticoagulated venous blood samples by SQ Blood DNA Kit II (D0714-250, Omega BioTek, Norcross, GA) according to the manufacturer's instructions. The polymerase chain reaction- (PCR-) ligase detection reaction method was employed to genotype all DNA samples. The PCR of the 7 target single-nucleotide polymorphisms was amplified by the primers shown in Table 1. A DNA sequencer was applied to detect the amplified products. No less than $10 \%$ of the samples were randomly picked out and retested to verify the validity of this procedure, and the results of the retested samples were consistent with those obtained from the original sample.

2.3. Statistical Analysis. All genotyping results in partial seizures patients and controls were tested for Hardy-Weinberg
Equilibrium (HWE) by applying Chi-square test ( $\chi^{2}$ test). Chi-square statistics ( $\chi^{2}$ test) were used to compare the statistical differences in genotype distributions and allele frequencies between patients and controls. The associations between the genotypes and the partial seizures were evaluated via the odds ratio (OR), with a $95 \%$ confidence interval (CI) (95\% CI), and a two-tailed $p$ value below 0.05 was considered statistically significant. All statistical analyses were operated by SPSS 17.0 for Windows (SPSS Inc., Chicago, IL, USA).

\section{Results}

The distributions of all genotypes were in accordance with the Hardy-Weinberg Equilibrium in control groups.

3.1. NLRP1 Polymorphism. The distributions of NLRP1 (rs8079034 (C>T) and rs878329 (G>C)) genotypes and alleles in the partial seizures patients and the controls are presented in Table 2. The male and female distributions of rs8079034 $(\mathrm{C}>\mathrm{T})$ and rs878329 $(\mathrm{G}>\mathrm{C})$ genotypes and alleles in the patients and the controls are shown in Tables 3 and 4, respectively. There was no statistically significant difference between patients and controls for the genotype and allele distributions of rs8079034 (C>T) polymorphisms, including all samples, males and females. Between the partial seizures patients and the healthy controls, there was a significant difference in the distribution of the genotypes rs878329 $(\mathrm{G}>\mathrm{C})(p=0.009)$. The frequency of genotype with $\mathrm{C}(\mathrm{CG}+\mathrm{CC})$ was significantly lower among the patients with partial seizures patients relative to the controls ( $\mathrm{OR}=2.033,95 \% \mathrm{CI}=1.290-3.204$; $p=0.002$ for GC $+\mathrm{CC}$ versus GG). Moreover, the $\mathrm{C}$ allele showed a significant association with partial seizures patients group $(\mathrm{OR}=1.801,95 \% \mathrm{CI}=1.217-2.667, p=0.003)$. Interestingly, the statistically significant difference of $\operatorname{rs} 878329(\mathrm{G}>\mathrm{C})$ genotype and allele frequency only existed among males $(\mathrm{OR}=2.492,95 \% \mathrm{CI}=1.266-4.906, p=0.008$ for $\mathrm{GC}$ versus $\mathrm{GG}$; OR $=2.542,95 \% \mathrm{CI}=1.344-4.810, p=0.004$ for $\mathrm{GC}+$ CC versus GG; OR = 2.216, 95\% CI $=1.286-3.818, p=0.004$ for $C$ versus $G$ ), while there was no statistically significant difference among females.

3.2. NLRP3 Polymorphism. We analyzed the allele and genotype frequencies of the rs4612666 (C>T), rs10754558 (C>G) and rs2027432 (C>T) for NLRP3 single-nucleotide polymorphisms between partial seizures patients and controls. There was no significant difference in the above mentioned genotypic distribution (Table 5). There was also no significant difference between different genders (data no shown).

3.3. P2X7R Polymorphism. The frequencies of the P2X7R of rs3751143 $(\mathrm{T}>\mathrm{G})$ and $\mathrm{rs} 208294(\mathrm{~A}>\mathrm{G})$ genotype in the case groups and the controls were investigated and we did not find differences in genotypic distribution or allele distribution (Table 6). There was also no significant difference between males or females (data no shown). 
TABLE 1: Primers of target genes used in the PCR.

\begin{tabular}{|c|c|c|c|}
\hline SNP & Ancestor allele & Primer sequence & Product size \\
\hline $\begin{array}{l}\text { NLRP1 } \\
\text { (rs8079034) }\end{array}$ & $\mathrm{C}$ & $\begin{array}{l}5^{\prime} \text {-TGATGGTCTGATTCATGCCC-3' (forward) } \\
5^{\prime} \text {-GTAGTTGCTAGGCAATGCGG-3' (reverse) }\end{array}$ & $98 \mathrm{bp}$ \\
\hline $\begin{array}{l}\text { NLRP1 } \\
(\text { rs878329) }\end{array}$ & G & $\begin{array}{l}5^{\prime} \text {-ATCCACTCAACTCCCTCAAC-3' (forward) } \\
5^{\prime} \text {-CAACATGAGACCAGTCCTTG-3' (reverse) }\end{array}$ & $111 \mathrm{bp}$ \\
\hline $\begin{array}{l}\text { NLRP3 } \\
(\text { rs4612666) }\end{array}$ & $\mathrm{C}$ & $\begin{array}{l}5^{\prime} \text {-TTCCTTTTCCATTTGGTGGA-3' (forward) } \\
5^{\prime} \text {-AGATGGTGGTGGTGATGGTT-3' (reverse) }\end{array}$ & $200 \mathrm{bp}$ \\
\hline $\begin{array}{l}\text { NLRP3 } \\
\text { (rs10754558) }\end{array}$ & $\mathrm{C}$ & $\begin{array}{l}5^{\prime} \text {-GGTCACCAAGAGGAACATCC-3' (forward) } \\
5^{\prime} \text {-GGTGGAGTGTCGGAGAAGAG-3 }{ }^{\prime} \text { (reverse) }\end{array}$ & $160 \mathrm{bp}$ \\
\hline $\begin{array}{l}\text { NLRP3 } \\
\text { (rs2027432) }\end{array}$ & $\mathrm{C}$ & $\begin{array}{c}5^{\prime} \text {-TGAGGCCTTTAAAACAGAGC-3' (forward) } \\
5^{\prime} \text {-GAGCATTCTCTCTGCAGTTC-3' (reverse) }\end{array}$ & $116 \mathrm{bp}$ \\
\hline $\begin{array}{l}\text { P2RX7 } \\
\text { (rs3751143) }\end{array}$ & $\mathrm{T}$ & $\begin{array}{l}5^{\prime} \text {-TTCCTGGACAACCAGAGGAG-3' (forward) } \\
5^{\prime} \text {-TCCTGGTAGAGCAGGAGGAA-3' (reverse) }\end{array}$ & $240 \mathrm{bp}$ \\
\hline $\begin{array}{l}\text { P2RX7 } \\
(\text { rs208294) }\end{array}$ & A & $\begin{array}{l}5^{\prime} \text {-GTTAGGATGGGCTTGATGGA-3' (forward) } \\
5^{\prime} \text {-CACCAGGCAGAGACTTCACA-3' (reverse) }\end{array}$ & $227 \mathrm{bp}$ \\
\hline
\end{tabular}

TABLE 2: Genotypic and allelic distribution of the NLRP1 gene between all patients $(n=163)$ and controls $(n=201)$.

\begin{tabular}{|c|c|c|c|c|c|c|}
\hline SNP & Genotype/allele & Case (\%) & Control (\%) & $p$ value $^{\mathrm{a}}\left(\chi^{2}\right)$ & OR (95\% CI) & $p$ value $^{\mathrm{b}}$ \\
\hline \multirow{6}{*}{ rs8079034 } & $\mathrm{CC}$ & $120(73.6)$ & $153(76.1)$ & $0.752(0.569)$ & 1.00 & Referent \\
\hline & $\mathrm{CT}$ & $37(22.7)$ & $43(21.4)$ & & $0.911(0.553-1.503)$ & 0.717 \\
\hline & $\mathrm{TT}$ & $6(3.7)$ & $5(2.5)$ & & $0.654(0.195-2.193)$ & 0.491 \\
\hline & $\mathrm{CT}+\mathrm{TT}$ & $43(26.4)$ & $48(23.9)$ & $0.584(0.300)$ & $0.876(0.544-1.409)$ & 0.584 \\
\hline & $\mathrm{C}$ & $277(85.0)$ & $349(86.8)$ & $0.475(0.509)$ & 1.00 & Referent \\
\hline & $\mathrm{T}$ & $49(15.0)$ & $53(13.2)$ & & $0.858(0.565-1.306)$ & 0.476 \\
\hline \multirow{6}{*}{ rs878329 } & GG & $123(75.5)$ & $121(60.2)$ & $0.009^{*}(9.486)$ & 1.00 & Referent \\
\hline & GC & $35(21.5)$ & $70(34.8)$ & & $2.033(1.262-3.276)$ & $0.004^{*}$ \\
\hline & $\mathrm{CC}$ & $5(3.0)$ & $10(5.0)$ & & $2.033(0.675-6.123)$ & 0.207 \\
\hline & $\mathrm{GC}+\mathrm{CC}$ & $40(24.5)$ & $80(39.8)$ & $0.002^{*}(9.486)$ & $2.033(1.290-3.204)$ & $0.002^{*}$ \\
\hline & G & $281(86.2)$ & $312(77.6)$ & $0.003^{*}(8.782)$ & 1.00 & Referent \\
\hline & $\mathrm{C}$ & $45(13.8)$ & $90(22.4)$ & & $1.801(1.217-2.667)$ & $0.003^{*}$ \\
\hline
\end{tabular}

CI, confidence interval; OR, odds ratio.

${ }^{a} p$ value for genotype and allele frequencies in cases and controls using 2 -sided $\chi^{2}$ test.

${ }^{\mathrm{b}} p$ values adjusted by age and gender using logistic regression.

${ }^{*} p<0.05$.

\section{Discussion}

Epilepsy is a chronic neurological disorder, characterized by electrical disturbances in the brain. The important roles of inflammatory processes in relation to modulatory effects of neurotoxic neurotransmitters discharged during excitation or inflammation in the central nervous system have been proved over the last decade, which showed relation to epilepsy or seizures. Large numbers of inflammatory mediators, especially the release of proinflammatory cytokines IL- $1 \beta$, are considered essential in the initiation and regulation of inflammation. Inflammasomes, one type of multiprotein complexes, have been proposed to play key roles in activation of caspase-1 from its inactive proprotein, which then promote the maturation of inflammatory cytokines IL- $1 \beta$.

Inflammasome consists of proinflammatory caspase(s), NLRP family members containing pyrin domain, and an adaptor protein that facilitates the interaction between them.
NLRP1 and NLRP3 are the two mostly studied members of inflammasomes and are critical in immune responses. Based on these findings, we explored the relevance between NLRP1 (rs8079034, rs878329) and NLRP3 (rs4612666, rs10754558, and rs2027432) gene polymorphisms and partial seizures in a Chinese Han population for the first time. It was found that there was a significant correlation between NLRP1 (rs878329, $\mathrm{G}>\mathrm{C}$ ) polymorphism and partial seizures in a Chinese Han population. It is consistent with the results of the study carried out by Tan et al., which proved NLRP1 inflammasome was activated in patients with mesial temporal lobe epilepsy [14]. Likewise, in one study about rheumatoid arthritis in Han Chinese, Sui et al. [20] found that the NLRP1 (rs878329, G>C) polymorphism was a risk factor for rheumatoid arthritis. Another study performed by Ekman et al. [21] showed that NLRP1 (rs878329, G>C) polymorphism correlated with psoriasis susceptibility. These results showed that rs878329 $(\mathrm{G}>\mathrm{C})$ might be a vital gene in the function of NLRP1. 
TABLE 3: Genotypic and allelic distribution of the NLRP1 gene between male patients $(n=89)$ and controls $(n=99)$.

\begin{tabular}{|c|c|c|c|c|c|c|}
\hline SNP & Genotype/allele & Case (\%) & Control (\%) & $p$ value $^{\mathrm{a}}\left(\chi^{2}\right)$ & OR $(95 \% \mathrm{CI})$ & $p$ value $^{\mathrm{b}}$ \\
\hline \multirow{6}{*}{ rs8079034 } & $\mathrm{CC}$ & $63(70.8)$ & $78(78.8)$ & $0.432(1.678)$ & 1.00 & Referent \\
\hline & CT & $23(25.8)$ & $18(18.2)$ & & $0.632(0.314-1.274)$ & 0.199 \\
\hline & TT & $3(3.4)$ & $3(3.0)$ & & $0.808(0.158-4.140)$ & 0.798 \\
\hline & $\mathrm{CT}+\mathrm{TT}$ & $26(29.2)$ & $21(21.2)$ & $0.206(1.600)$ & $0.652(0.336-1.267)$ & 0.207 \\
\hline & $\mathrm{C}$ & $149(83.7)$ & $174(87.9)$ & $0.246(1.347)$ & 1.00 & Referent \\
\hline & $\mathrm{T}$ & $29(16.3)$ & $24(12.1)$ & & $0.709(0.395-1.270)$ & 0.247 \\
\hline \multirow{6}{*}{ rs878329 } & GG & $69(77.5)$ & $57(57.6)$ & $0.015^{*}(8.466)$ & 1.00 & Referent \\
\hline & GC & 17 (19.1) & $35(35.4)$ & & $2.492(1.266-4.906)$ & $0.008^{*}$ \\
\hline & $\mathrm{CC}$ & $3(3.4)$ & $7(7.0)$ & & $2.825(0.698-11.423)$ & 0.145 \\
\hline & $\mathrm{GC}+\mathrm{CC}$ & $20(22.5)$ & $42(42.4)$ & $0.004^{*}(8.441)$ & $2.542(1.344-4.810)$ & $0.004^{*}$ \\
\hline & G & $155(87.1)$ & $149(75.3)$ & $0.004^{*}(8.467)$ & 1.00 & Referent \\
\hline & $\mathrm{C}$ & $23(12.9)$ & $49(24.7)$ & & $2.216(1.286-3.818)$ & $0.004^{*}$ \\
\hline
\end{tabular}

CI, confidence interval; OR, odds ratio.

${ }^{a} p$ value for genotype and allele frequencies in cases and controls using 2-sided $\chi^{2}$ test.

${ }^{\mathrm{b}} p$ values adjusted by age and gender using logistic regression.

${ }^{*} p<0.05$.

TABLE 4: Genotypic and allelic distribution of the NLRP1 gene between female patients $(n=74)$ and controls $(n=102)$.

\begin{tabular}{|c|c|c|c|c|c|c|}
\hline SNP & Genotype/allele & Case (\%) & Control (\%) & $p$ value $^{\mathrm{a}}\left(\chi^{2}\right)$ & OR $(95 \% \mathrm{CI})$ & $p$ value $^{\mathrm{b}}$ \\
\hline \multirow{6}{*}{ rs8079034 } & $\mathrm{CC}$ & $57(77.0)$ & $75(73.5)$ & $0.513(1.336)$ & 1.00 & Referent \\
\hline & $\mathrm{CT}$ & $14(18.9)$ & $25(24.5)$ & & $1.357(0.648-2.843)$ & 0.418 \\
\hline & $\mathrm{TT}$ & $3(4.1)$ & $2(2.0)$ & & $0.507(0.082-3.133)$ & 0.465 \\
\hline & $\mathrm{CT}+\mathrm{TT}$ & $17(23.0)$ & $27(26.5)$ & $0.597(0.280)$ & $1.207(0.601-2.425)$ & 0.597 \\
\hline & $\mathrm{C}$ & $128(86.5)$ & $175(86.8)$ & $0.851(0.035)$ & 1.00 & Referent \\
\hline & $\mathrm{T}$ & $20(13.5)$ & $29(14.2)$ & & $1.061(0.574-1.959)$ & 0.851 \\
\hline \multirow{6}{*}{ rs878329 } & GG & $54(73.0)$ & $64(62.7)$ & $0.350(2.009)$ & 1.00 & Referent \\
\hline & GC & $18(24.3)$ & $35(34.3)$ & & $4.641(0.836-3.219)$ & 0.150 \\
\hline & $\mathrm{CC}$ & $2(2.7)$ & $3(3.0)$ & & $1.266(0.204-7.854)$ & 0.800 \\
\hline & $\mathrm{GC}+\mathrm{CC}$ & $20(27.0)$ & $38(37.3)$ & $0.154(2.031)$ & $1.603(0.836-3.075)$ & 1.603 \\
\hline & G & $126(85.1)$ & $163(79.9)$ & $0.206(1.599)$ & 1.00 & Referent \\
\hline & $\mathrm{C}$ & $22(14.9)$ & $41(20.1)$ & & $1.441(0.817-2.542)$ & 0.208 \\
\hline
\end{tabular}

$\mathrm{CI}$, confidence interval; OR, odds ratio.

${ }^{\mathrm{a}} p$ value for genotype and allele frequencies in cases and controls using 2 -sided $\chi^{2}$ test.

${ }^{\mathrm{b}} p$ values adjusted by age and gender using logistic regression.

However, we did not found any significant difference of the rs4612666 (C>T), rs10754558 (C>G) and rs2027432 (C>T) for NLRP3 single-nucleotide polymorphisms between partial seizures patients and controls. The difference between the function of NLRP1 and NLRP3 polymorphism on the epilepsy susceptibility may result from that their cell-specific expression and divergent biological functions; that is, NLRP1 mainly exists in neurons and is essential for the pyroptotic cell death in epilepsy pathogenesis, whereas the NLRP3 is mainly expressed in microglia and is responsive to immune activation. The exact mechanism of the induced activation of the NLRP1 and NLRP3 inflammasomes is unclear. One possible mechanism is that the potassium efflux induces the inflammasome formation. P2X7R is one of important purinergic receptors, promoting the potassium efflux activated by the excessive ATP release. Studies have proved that the P2X7R plays a pivotal role in central nervous system function and may contribute to the progression of several neuropsychiatric disorders, including epilepsy. Based on these clues, we also investigated the relationship between P2X7R (rs3751143, T>G and rs208294, A>G) polymorphisms and partial seizures. Unfortunately, there were no significant differences for the genotypic distribution or allele distribution of rs3751143 $(\mathrm{T}>\mathrm{G})$ and rs208294 $(\mathrm{A}>\mathrm{G})$ genotypes of P2X7R in the case groups and the controls. These results may be explained by the limitation of this study: the sample size in each genotype is too small to get sufficient statistical power for detecting the slight effect.

The epidemiology of epilepsy in humans indicates that the gender-specific incidence was slightly higher for males than for females which can be explained by the fact that males are more liable to be exposed to the higher risk factors for epilepsy such as central nervous system infection, head injury, and stroke [22]. Accordingly, one of the surprising 
TABLE 5: Genotypic and allelic distribution of the NLRP3 gene between all patients $(n=163)$ and controls $(n=201)$.

\begin{tabular}{|c|c|c|c|c|c|c|}
\hline SNP & Genotype/allele & Case (\%) & Control (\%) & $p$ value $^{\mathrm{a}}\left(\chi^{2}\right)$ & OR $(95 \% \mathrm{CI})$ & $p$ value $^{\mathrm{b}}$ \\
\hline \multirow{6}{*}{ rs4612666 } & $\mathrm{CC}$ & $44(27.0)$ & $59(29.4)$ & $0.220(3.026)$ & 1.00 & Referent \\
\hline & CT & $90(55.2)$ & $94(46.8)$ & & $0.779(0.479-1.266)$ & 0.313 \\
\hline & TT & $29(17.8)$ & $48(23.9)$ & & $1.234(0.675-2.258)$ & 0.495 \\
\hline & $\mathrm{CT}+\mathrm{TT}$ & $119(73.0)$ & $142(70.6)$ & $0.584(0.300)$ & $0.890(0.562-1.410)$ & 0.619 \\
\hline & $\mathrm{C}$ & $178(54.6)$ & $212(52.7)$ & $0.616(0.252)$ & 1.00 & Referent \\
\hline & $\mathrm{T}$ & $148(45.4)$ & $190(47.3)$ & & $1.078(0.804-1.445)$ & 0.616 \\
\hline \multirow{6}{*}{ rs10754558 } & $\mathrm{CC}$ & $50(30.7)$ & $76(37.8)$ & $0.313(2.322)$ & 1.00 & Referent \\
\hline & CG & $84(51.5)$ & $89(44.3)$ & & $0.697(0.438-1.110)$ & 0.128 \\
\hline & GG & $29(17.8)$ & $36(17.9)$ & & $0.817(0.446-1.496)$ & 0.512 \\
\hline & $\mathrm{CG}+\mathrm{GG}$ & $113(69.3)$ & $125(62.2)$ & $0.155(2.025)$ & $0.728(0.470-1.128)$ & 0.155 \\
\hline & $\mathrm{C}$ & $184(56.4)$ & $241(60.0)$ & $0.340(0.912)$ & 1.00 & Referent \\
\hline & G & $142(43.6)$ & $161(40.0)$ & & $0.866(0.644-1.164)$ & 0.340 \\
\hline \multirow{6}{*}{ rs2027432 } & $\mathrm{CC}$ & $151(92.6)$ & $180(89.5)$ & $0.549(1.200)$ & 1.00 & Referent \\
\hline & CT & $11(6.8)$ & $20(10.0)$ & & $1.525(0.708-3.284)$ & 0.281 \\
\hline & TT & $1(0.6)$ & $1(0.5)$ & & $0.839(0.052-13.525)$ & 0.901 \\
\hline & $\mathrm{CT}+\mathrm{TT}$ & $12(7.4)$ & $21(10.5)$ & $0.308(1.040)$ & $1.468(0.699-3.082)$ & 0.310 \\
\hline & $\mathrm{C}$ & $313(96.0)$ & $380(94.5)$ & $0.352(0.867)$ & 1.00 & Referent \\
\hline & $\mathrm{T}$ & $13(4.0)$ & $22(5.5)$ & & $1.394(0.691-2.812)$ & 0.354 \\
\hline
\end{tabular}

$\mathrm{CI}$, confidence interval; OR, odds ratio.

${ }^{a} p$ value for genotype and allele frequencies in cases and controls using 2 -sided $\chi^{2}$ test.

${ }^{\mathrm{b}} p$ values adjusted by age and gender using logistic regression.

TABLE 6: Genotypic and allelic distribution of the P2RX7 gene between all patients $(n=163)$ and controls $(n=201)$.

\begin{tabular}{|c|c|c|c|c|c|c|}
\hline SNP & Genotype/allele & Case (\%) & Control (\%) & $p$ value $^{\mathrm{a}}\left(\chi^{2}\right)$ & OR $(95 \% \mathrm{CI})$ & $p$ value $^{\mathrm{b}}$ \\
\hline \multirow{6}{*}{ rs3751143 } & $\mathrm{TT}$ & $94(57.7)$ & $127(63.2)$ & $0.451(1.592)$ & 1.00 & Referent \\
\hline & TG & $59(36.2)$ & $66(32.8)$ & & $0.828(0.533-1.287)$ & 0.401 \\
\hline & GG & $10(6.1)$ & $8(4.0)$ & & $0.592(0.225-1.558)$ & 0.288 \\
\hline & $\mathrm{GT}+\mathrm{GG}$ & $69(42.3)$ & $74(36.8)$ & $0.284(1.148)$ & $0.794(0.520-1.211)$ & 0.284 \\
\hline & $\mathrm{T}$ & $247(75.8)$ & $320(79.6)$ & $0.215(1.537)$ & 1.00 & Referent \\
\hline & G & $79(24.2)$ & $82(20.4)$ & & $0.801(0.564-1.138)$ & 0.215 \\
\hline \multirow{6}{*}{ rs208294 } & $\mathrm{AA}$ & $58(35.6)$ & $69(34.3)$ & $0.741(0.599)$ & 1.00 & Referent \\
\hline & AG & $83(50.9)$ & $99(49.3)$ & & $1.003(0.636-1.580)$ & 0.991 \\
\hline & GG & $22(13.5)$ & $33(16.4)$ & & $1.261(0.663-2.397)$ & 0.480 \\
\hline & $\mathrm{AG}+\mathrm{GG}$ & $105(64.4)$ & $132(65.7)$ & $0.830(0.062)$ & $1.057(0.685-1.630)$ & 0.803 \\
\hline & $\mathrm{A}$ & $199(61.0)$ & $237(59.0)$ & $0.568(0.327)$ & 1.00 & Referent \\
\hline & G & $127(39.0)$ & $165(41.0)$ & & $1.091(0.809-1.470)$ & 0.568 \\
\hline
\end{tabular}

CI, confidence interval; OR, odds ratio.

${ }^{a} p$ value for genotype and allele frequencies in cases and controls using 2 -sided $\chi^{2}$ test.

${ }^{\mathrm{b}} p$ values adjusted by age and gender using logistic regression.

results of this research is that the genetic variation of rs878329 $(\mathrm{G}>\mathrm{C})$ seems to contribute to the susceptibility of partial seizures, while no difference was observed between female patients and controls. Additionally, sex hormones, such as androgen, estrogen, and progesterone, along with their metabolites, play a role in brain network formation and can affect the activity of inflammasomes and neuroimmune system. Therefore, the gender difference found in the present study can be at least partially attributed to the interaction between steroid hormones and inflammasomes in neuroinflammatory process [23-25].

\section{Conclusion}

In summary, to our knowledge, this is the first report exploring the potential relevance on molecular mechanism between NLPR1, NLRP3, and P2X7R polymorphisms and partial seizures in a Chinese Han population, and our data suggest that there was a significant correlation between NLRP1 (rs878329, G>C) polymorphism and partial seizures in the study population. Although our data suggest a potential role of NLPR1 polymorphisms in susceptibility to seizures, these results need to be consolidated by further studies involving other ethnics and a larger group of seizures patients. 


\section{Conflicts of Interest}

The authors declare that there are no conflicts of interest regarding the publication of this paper.

\section{Acknowledgments}

The study was supported by the National Natural Science Foundation of China (no. 81602846), Natural Science Foundation of Shandong Province (no. ZR2016HQ21), and Excellent Youth Foundation Program for Developing the Health of Lianyungang (QN1601).

\section{References}

[1] A. K. Ngugi, C. Bottomley, I. Kleinschmidt, J. W. Sander, and C. R. Newton, "Estimation of the burden of active and life-time epilepsy: a meta-analytic approach," Epilepsia, vol. 51, no. 5, pp. 883-890, 2010.

[2] World Health Organization (WHO), "Epilepsy," Fact Sheet 999, 2012.

[3] J. A. Wilden and A. A. Cohen-Gadol, "Evaluation of first nonfebrile seizures," American Family Physician, vol. 86, no. 4, pp. 334-340, 2012.

[4] K. Kobayashi, S. Maniwa, T. Ogino, H. Yoshinaga, Y. Ohtsuka, and E. Oka, "Myoclonic seizures combined with partial seizures and probable pathophysiology of secondary bilateral synchrony," Clinical Neurophysiology, vol. 111, no. 10, pp. 1813-1816, 2000.

[5] R. Vassar, B. D. Bennett, S. Babu-Khan et al., " $\beta$-Secretase cleavage of Alzheimer's amyloid precursor protein by the transmembrane aspartic protease BACE," Science, vol. 286, no. 5440, pp. 735-741, 1999.

[6] A. Vezzani and T. Granata, "Brain inflammation in epilepsy: experimental and clinical evidence," Epilepsia, vol. 46, no. 11, pp. 1724-1743, 2005.

[7] T. Granata, H. Cross, W. Theodore, and G. Avanzini, "Immunemediated epilepsies," Epilepsia, vol. 52, supplement 3, pp. 5-11, 2011.

[8] A. Vezzani, J. French, T. Bartfai, and T. Z. Baram, "The role of inflammation in epilepsy," Nature Reviews Neurology, vol. 7, no. 1, pp. 31-40, 2011.

[9] B. Chowdhury, A. L. David, C. Thrasivoulou, D. L. Becker, D. L. Bader, and T. T. Chowdhury, "Tensile strain increased COX2 expression and PGE2 release leading to weakening of the human amniotic membrane," Placenta, vol. 35, no. 12, pp. 10571064, 2014.

[10] F. Martinon, K. Burns, and J. Tschopp, “The Inflammasome: a molecular platform triggering activation of inflammatory caspases and processing of proIL- $\beta$," Molecular Cell, vol. 10, no. 2, pp. 417-426, 2002.

[11] K. Schroder and J. Tschopp, “The inflammasomes," Cell, vol.140, no. 6, pp. 821-832, 2010.

[12] F. L. van de Veerdonk, M. G. Netea, C. A. Dinarello, and L. A. B. Joosten, "Inflammasome activation and IL- $1 \beta$ and IL-18 processing during infection," Trends in Immunology, vol. 32, no. 3, pp. 110-116, 2011.

[13] M. T. Ganter, J. Roux, B. Miyazawa et al., "Interleukin-1beta causes acute lung injury via alphavbeta5 and alphavbeta6 integrin-dependent mechanisms," Circulation Research, vol. 102, no. 7, pp. 804-812, 2008.
[14] C.-C. Tan, J.-G. Zhang, M.-S. Tan et al., "NLRP1 inflammasome is activated in patients with medial temporal lobe epilepsy and contributes to neuronal pyroptosis in amygdala kindlinginduced rat model," Journal of Neuroinflammation, vol. 12, pp. 18-24, 2015.

[15] X.-F. Meng, L. Tan, M.-S. Tan et al., "Inhibition of the NLRP3 inflammasome provides neuroprotection in rats following amygdala kindling-induced status epilepticus," Journal of Neuroinflammation, vol. 11, pp. 212-217, 2014.

[16] M. Maroso, S. Balosso, T. Ravizza, J. Liu, M. E. Bianchi, and A. Vezzani, "Interleukin-1 type 1 receptor/Toll-like receptor signalling in epilepsy: the importance of IL-1beta and highmobility group box 1," Journal of Internal Medicine, vol. 270, no. 4, pp. 319-326, 2011.

[17] R. Muñoz-Planillo, P. Kuffa, G. Martínez-Colón, B. Smith, T. Rajendiran, and G. Núñez, " $\mathrm{K}(+)$ efflux is the common trigger of NLRP3 inflammasome Aativation by bacterial toxins and particulate matter," Immunity, vol. 38, no. 6, pp. 1142-1153, 2013.

[18] B. Sperlágh and P. Illes, "P2X7 receptor: an emerging target in central nervous system diseases," Trends in Pharmacological Sciences, vol. 35, no. 10, pp. 537-547, 2014.

[19] R. Bartlett, L. Stokes, and R. Sluyter, "The P2X7 receptor channel: recent developments and the use of P2X7 antagonists in models of disease," Pharmacological Reviews, vol. 66, no. 3, pp. 638-675, 2014.

[20] J. Sui, H. Li, Y. Fang et al., "NLRP1 gene polymorphism influences gene transcription and is a risk factor for rheumatoid arthritis in han chinese," Arthritis and Rheumatism, vol. 64, no. 3, pp. 647-654, 2012.

[21] A.-K. Ekman, D. Verma, M. Fredrikson, C. Bivik, and C. Enerbäck, "Genetic variations of NLRP1: susceptibility in psoriasis," British Journal of Dermatology, vol. 171, no. 6, pp. 15171520, 2014.

[22] I. A. W. Kotsopoulos, T. van Merode, F. G. H. Kessels, M. C. T. F. M. de Krom, and J. A. Knottnerus, "Systematic review and meta-analysis of incidence studies of epilepsy and unprovoked seizures," Epilepsia, vol. 43, no. 11, pp. 1402-1409, 2002.

[23] Y.-J. Dai, Z.-H. Xu, B. Feng et al., "Gender difference in acquired seizure susceptibility in adult rats after early complex febrile seizures," Neuroscience Bulletin, vol. 30, no. 6, pp. 913-922, 2014.

[24] M. Schmidt, H. Naumann, C. Weidler, M. Schellenberg, S. Anders, and R. H. Straub, "Inflammation and sex hormone metabolism," Annals of the New York Academy of Sciences, vol. 1069, pp. 236-246, 2006.

[25] A. Verrotti, G. Latini, R. Manco, M. De Simone, and F. Chiarelli, "Influence of sex hormones on brain excitability and epilepsy," Journal of Endocrinological Investigation, vol. 30, no. 9, pp. 797803, 2007. 

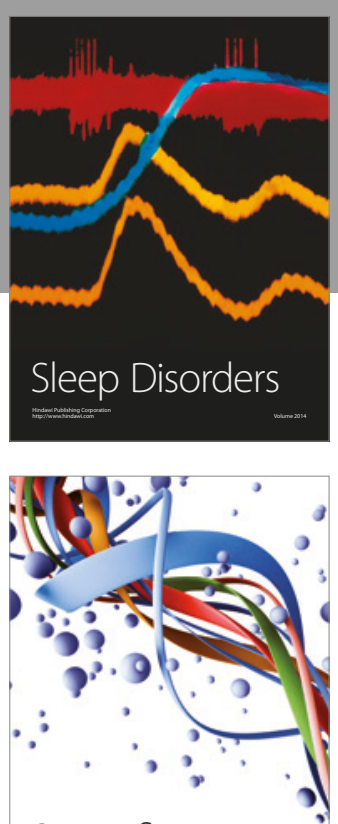

Scientifica
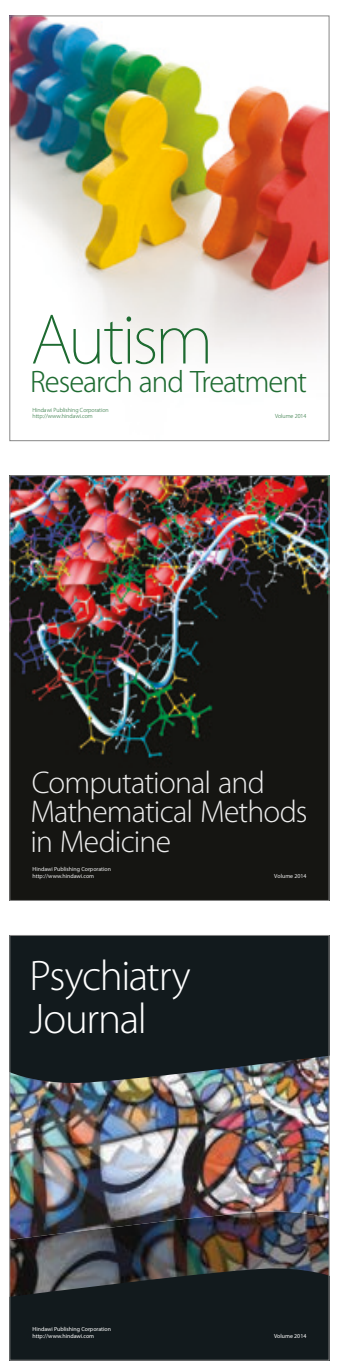
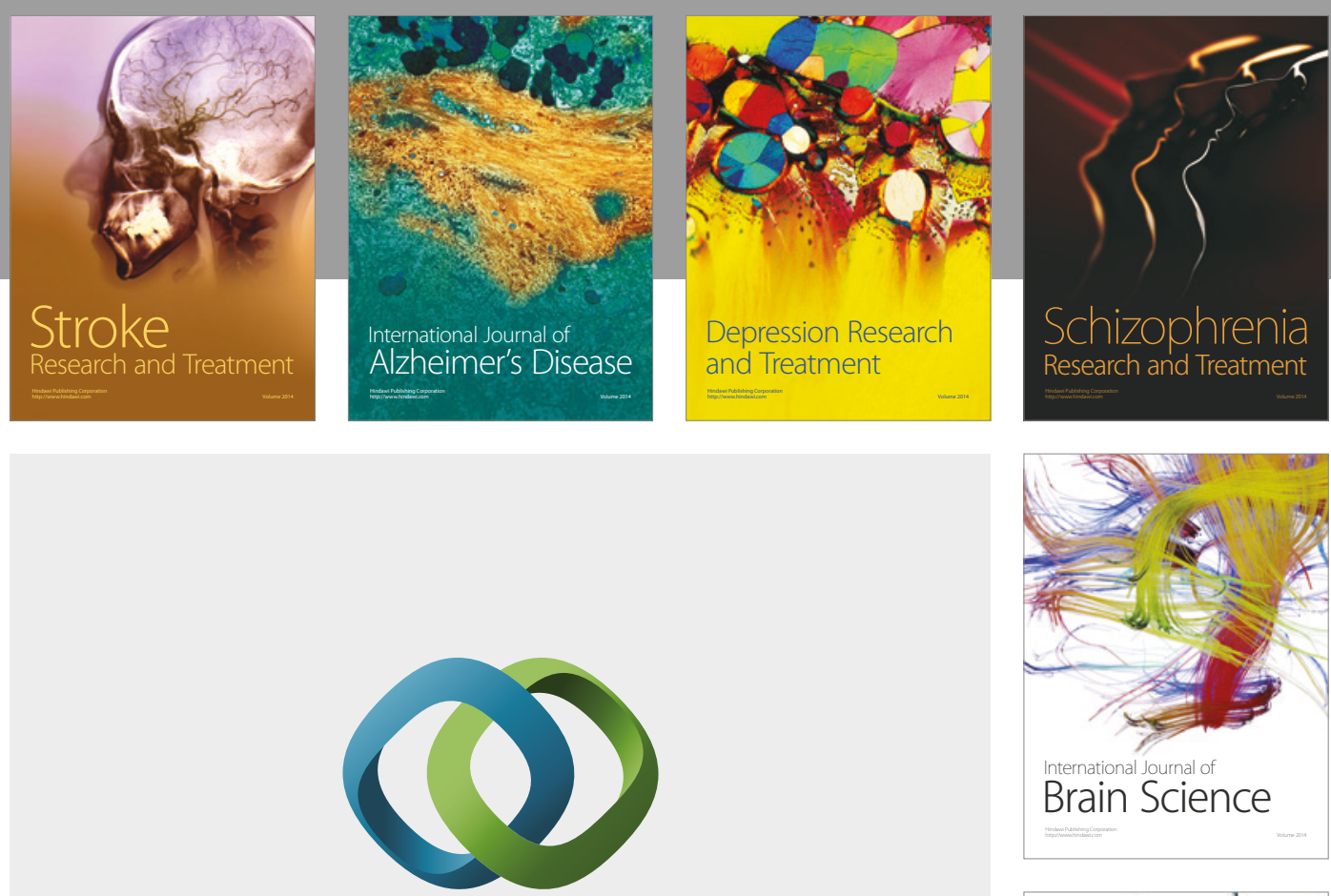

\section{Hindawi}

Submit your manuscripts at

https://www.hindawi.com
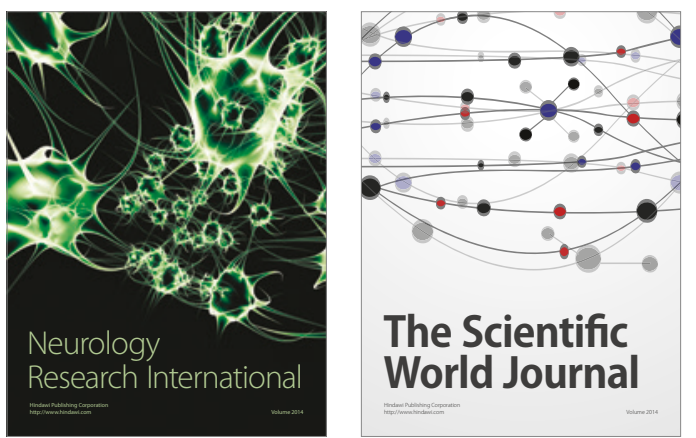

The Scientific World Journal

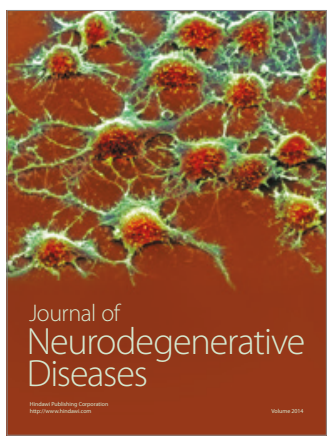

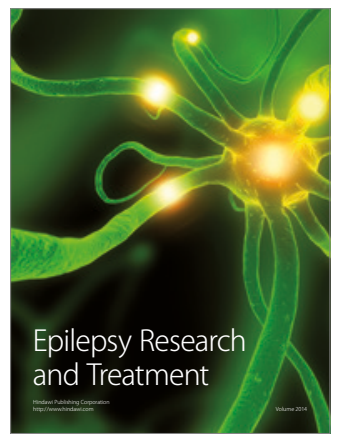

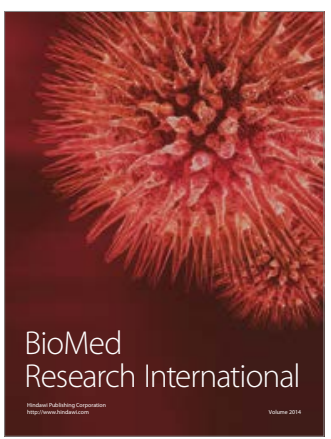

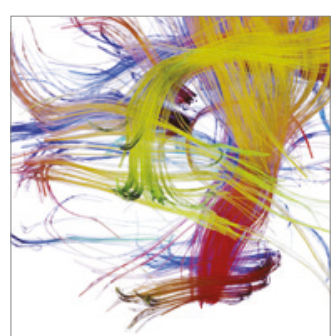

Brain Science

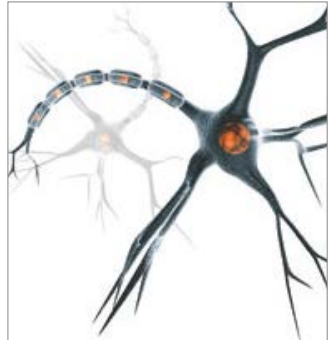

Neural Plasticity
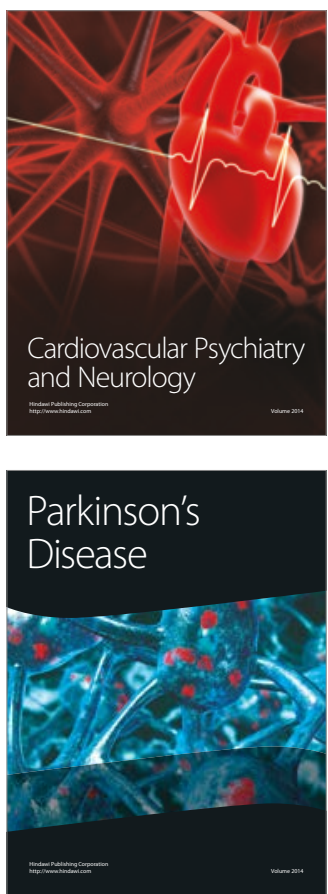